\title{
Mãos Livres para Cozinhar: affordances e inovações no aplicativo Culinary Pal
}

FREE HANDS TO COOK: AFFORFANCES AND INNOVATIONS IN THE CULINARY PAL APP

\section{Marcelo Freire}

Doutor em Comunicação e Cultura Contemporâneas pela Universidade Federal da Bahia. Professor do Programa de Pós-Graduação em Comunicação e da graduação em Jornalismo da Universidade Federal de Ouro Preto. Coordena o Grupo de Pesquisa Convergência e Jornalismo (ConJor) e o Laboratório de Inovação em Jornalismo (Labin).

Email: marcelofreire@ufop.edu.br

\section{Ana Paula Martins Pereira}

Mestranda do Programa de Pós-graduação em Comunicação da Universidade Federal de Ouro Preto. Integra o Grupo de Pesquisa Convergência e Jornalismo (ConJor).

Email:apaulamartinsp@gmail.com

Recebido em 29/06/2018. Aprovado em 02/10/2018.

\section{Resumo}

Os saberes culinários são transmitidos através da oralidade e pelos cadernos de receitas. Este artigo analisa as possíveis transformações no modo de registro, consulta e divulgação de receitas desse meio tradicional para os aplicativos para dispositivos móveis. O objeto de estudos é o Culinary Pal, aplicativo que funciona por comando de voz, possibilitando que as mãos fiquem livres para cozinhar. Neste texto consideramos os aplicativos como uma remediação dos cadernos manuscritos. Por meio da discussão sobre affordances, materialidade e inovação e tendo como metodologia a Análise de Conteúdo, o trabalho traça uma comparação entre as funcionalidades do aplicativo e as características dos tradicionais cadernos de receitas.

Palavras-chave: Aplicativos para dispositivos móveis. Affordances. Caderno de receitas.

\section{Abstract}

Culinary knowledge is transmitted through orality and recipe books. This article examines the possible transformations in the way of recording, querying, and disseminating recipes from this traditional medium for mobile applications. The object of study is the Culinary Pal, an application that works by voice command, allowing the hands to be free to cook. In this text we consider the applications as a remediation of the manuscript notebooks. Through the discussion about affordances, materiality and innovation and having as a methodology the Content Analysis, the work traces a comparison between the functionalities of the application and the characteristics of the traditional recipe books.

Keywords: Mobile apps. Affordances. Recipe notebook. 


\section{Introdução}

A comida é um elemento constituidor da identidade de um povo, sendo um ato cultural e social. "A alimentação revela e preserva os costumes, localizando-os em suas respectivas culturas" (ORTIZ, 1994, p. 77). Por ser, também, um reflexo de seu tempo, a gastronomia passa constantemente por transformações, especialmente no que tange o modo de transmissão de conhecimentos, ingredientes e formas de cozinhar.

Como a culinária faz parte da cultura de uma sociedade, estudar uma das formas como as pessoas utilizam e divulgam receitas na internet torna-se relevante para ajudar a entender as possíveis alterações e manutenções do meio tradicional de registro de receitas, por exemplo, os cadernos familiares, escritos à mão, para os aplicativos de gastronomia desenvolvidos para dispositivos móveis.

Este trabalho investiga as possíveis mudanças ocorridas no modo de registro, consulta e divulgação de receitas, bem como as características que são mantidas nesse processo, considerando o aplicativo como uma remediação (Bolter e Grusin, 2000) dos cadernos de receitas tradicionais. A análise é feita tomando como base as affordances envolvidas e a questão da materialidade. O objeto de pesquisa escolhido foi o aplicativo (app) Culinary Pal, que funciona por comando de voz, com a leitura de receitas, por meio de instruções dadas pelo usuário, possibilitando que as mãos fiquem livres para cozinhar, sem a necessidade de pegar ou olhar para o dispositivo a fim de consultar os ingredientes ou o modo de preparo.

Para a análise comparativa entre as funcionalidades do App e as características dos tradicionais cadernos de receitas, foi utilizada a metodologia de Análise de Conteúdo com a definição de unidades de registro, como a possibilidade de compartilhamento, a inclusão de pratos pelo usuário e a inserção de comentários.

\section{Dos cadernos de receitas aos aplicativos}

A culinária envolve questões que extrapolam os limites da cozinha. A gastronomia, portanto, pode ser analisada sob vários aspectos, como nutricionais, econômicos, sociais, históricos, culturais e emocionais. O saber culinário, com receitas, truques e preferências, em geral, é transmitido de geração a geração pelo aprendizado doméstico, bem como sistematizado em cadernos de receitas construídos no ambiente familiar. 
Parece bastante razoável afirmar que a maior parte do aprendizado [culinário] se dá por meio da observação cotidiana, em que se experimenta e se vivencia o ponto certo do doce, da calda, do refogado. O registro escrito é a simples decorrência desse saber apreendido por meio da experiência anterior (OLIVEIRA, 2013, p. 93).

Em geral, tais cadernos de receitas são confeccionados em cadernos comuns, pautados ou não, encadernados com grampos ou espirais, escritos à mão, capa comum ou de material mais resistente. Há a descrição de receitas que podem ser catalogadas por categorias (sobremesas, lanches, salgados, pratos principais, por exemplo), colocadas em ordem alfabética, cronologicamente ou de modo aleatório. "Essas anotações eram muitas vezes fruto da memória da pessoa que normalmente tinha a incumbência de cozinhar e preparar as receitas preferidas da família, ou de alguém que tivesse interesse por culinária.” (DEMETERCO, 1998, p. 106). Composto de receitas de família, criações próprias e com a possibilidade de inclusão de pratos de amigos, divulgados em programas de TV, por exemplo, e da colagem de recortes de revistas ou embalagens de produtos alimentícios. Nos cadernos de receitas são encontradas também receitas comentadas, revisadas, qualificadas de acordo com as preferências familiares. A organização visual individual, a grafia e a ordenação das receitas apresentadas constroem uma identidade editorial própria e culturalmente demarcada para estas peças.

Demeterco (1998) cita Maria Thereza Lacerda (1990), em sua obra Cartas da minha cozinha, para caracterizar o costume da "custódia" do caderno de receitas, muitas vezes passado como herança para alguma pessoa que se torna o "guardião" das receitas e dos segredos culinários da família:

[...] os cadernos de receitas, impropriamente chamados de livros, esquecidos em gavetas ao lado de velhos livros de orações repletos de fotografias, santinhos e flores secas, são despretensiosos e íntimos como um diário ingênuo de donzela. As receitas são manuscritas pelas próprias mulheres, encontrando-se uma ou outra caligrafia masculina ou de criança, a quem se atribuía esta tarefa para ocupar uma tarde chuvosa (LACERDA, 1990, p. 49 apud DEMETERCO, 1998, p. 116).

Com o passar do tempo e as mudanças urbanas, os costumes alimentares também sofreram alterações. "As tradições culinárias da vida doméstica são transformadas, e as receitas de família, de transmissão oral ou em cadernos manuscritos, são substituídas por escolas técnicas de culinária, por receitas nos rótulos dos produtos industriais e por programas de TV." 
(CARNEIRO, 2013 In: OLIVEIRA, 2013, p. 10). Os aplicativos de culinária, ao socializarem estas práticas e funcionarem como guias de ação na cozinha, podem ser considerados mais uma evolução desse processo, bem como uma remediação do caderno de receitas manuscritos.

O conceito de remediação é apresentado por Jay David Bolter e Richard Grusin (2000). Trata-se de uma mídia utilizando-se de características de outras anteriores, para facilitar o processo de compreensão do público ao novo suporte, restaurando as mídias já estabelecidas e forjando algo novo. "O vocábulo refere-se à ideia de que todas as novas mídias são dependentes de uma ou mais mídias anteriores, remodeladas e recompostas, para se tornarem uma nova mídia." (MARTINEZ, 2016, p. 324).

Nas palavras de Bolter e Grusin: remediação é "[...] a lógica formal pela qual a nova mídia refaz formulários de mídias anteriores." ${ }^{\prime \prime}$ (2000, p. 273. Tradução nossa). Martino (2014) também explica que:

A remediação ocorre quando, na tentativa de aproximar os indivíduos da realidade, uma mídia faz uso de várias outras. No caso específico da mídia digital, a dupla mediação está na possibilidade de aglutinar imagens, fotos, filmes, textos, sons e outras linguagens em uma outra mídia. É uma representação da representação. De onde o conceito de 're-mediação'. (MARTINO, 2014, p. 224).

A remediação não começou com a introdução dos meios de comunicação, mas ela se intensificou com o cenário das mídias, especialmente as digitais. "O que há de novo sobre as novas mídias vem das formas particulares em que reformulam os meios de comunicação mais antigos e as formas como os meios de comunicação antigos se reformulam para responder aos desafios das novas mídias.”2 (BOLTER; GRUSIN, 2000, p. 15).

A fim de analisar os aplicativos de gastronomia como uma remediação dos cadernos de receitas manuscritos, replicando suas particularidades em novos formatos para os dispositivos móveis, como o layout da receita, a descrição do passo a passo e a inserção de comentários, bem como inserindo inovações no processo de consulta culinária, optou-se por estudar o Culinary Pal.

Desde o primeiro PC, nos disseram que nossos computadores seriam usados em nossas cozinhas para armazenar receitas e quão maravilhoso seria. Não aconteceu. Telefones in-

1. No original: "[...] the formal logic by which new media refashion prior media forms."

2. No original: "What is new about new media comes from the particular ways in which they refashion older media and the ways in which older media refashion themselves to answer the challenges of new media." 
teligentes e tablets trouxeram os sonhos mais próximos. Agora, há uma solução de aplicativos com mãos livres e sem olhos. Culinary Pal receitas por voz não só recebe as receitas para você, mas usa controle de voz e lê ingredientes de receitas e instruções para você em seu próprio ritmo. (TAMXIR, 2014, grifos do autor. Tradução nossa).3

Ao se apresentar como o espaço para apresentação das receitas que deixa suas mãos e olhos livres, Culinary Pal explora os potenciais dos livros de culinária, mas favorece a modificação da experiência propiciada ao cruzar seus elementos com os potenciais dos dispositivos móveis digitais, principalmente, dos assistentes pessoais (como Siri ou Cortana) com a interface baseada em áudio.

\section{Culinary Pal}

O Culinary $\mathrm{Pal}^{4}$ é um aplicativo de cozinha ativado por voz. Desenvolvido por YiZRi's Inovations ${ }^{5}$ e está disponível gratuitamente para celulares e tablets Android $^{6}$ na versão $b e t a^{7}$. Segundo o desenvolvedor, é o primeiro aplicativo de receitas de mãos e olhos livres, utilizando tecnologias de reconhecimento de texto e fala (VoiceSee) ${ }^{8}$. Para usá-lo, além do próprio Culinary Pal no dispositivo, a pessoa também precisa ter instalado o Google Voice Search e utilizar fones de ouvido (com fio ou por bluetooth) com microfone embutido.

O app permite pesquisar pratos por comando de voz, ouvir ingredientes, tempo de preparo e passo a passo, sem a necessidade de olhar o celular para ler a receita, nem usar as mãos para prosseguir as instruções. Conforme descrito pelos desenvolvedores: "Não há mais impressão de receitas, tentando abrir o seu livro de receitas favorito, tentando seguir uma demonstração de culinária ou arriscar seu computador na cozinha. Nada mais

3. No original: "Ever since the first PC, we've been told our computers would be used in our kitchens to store recipes and how wonderful that will be. It didn't happen. Smart phones and tablets brought the dream closer. Now there's a hands-free and eyes-free app solution. Culinary Pal recipes by voice not only gets the recipes for you, but uses voice control and reads recipe ingredients and directions to you at your own pace."

4. Disponível em: <https://play.google.com/store/apps/details?id=com.yizri.voculinary\&hl=pt_BR>. Acesso em: 30 jul. 2017.

5. Disponível em: <http://www.yizri.com/home/>. Acesso em: 16 set. 2017.

6. O aplicativo não está disponível para IOS ou Windows Mobile.

7. Beta é a versão de um produto, no caso aplicativo, que ainda se encontra em fase de desenvolvimento, não está finalizado, com a possibilidade de apresentar erros, mas que, apesar disso, o desenvolvedor acredita que é possível de ser disponibilizado e utilizado pelo público. (VERSÃO BETA. In: WIKIPÉDIA - A enciclopédia livre. Disponível em: $<$ https://pt.wikipedia.org/wiki/Vers\%C3\%A3o_beta $>$. Acesso em: 28 set. 2017).

8. Disponível em: <http://www.yizri.com/products/voicesee-culinary-pal/> . Acesso em: 16 set. 2017. 
dedos sujos tocando no teclado ou transferindo bactérias e germes de comida para dispositivo.", ou nem do aparelho para a comida.

Há a possibilidade de o usuário controlar, por exemplo, o ritmo das instruções, pedir para repetir e seguir para o próximo passo por meio de comandos de voz. Com isso, as mãos ficam livres para a preparação das receitas, a atividade de cozinhar propriamente dita. O aplicativo está disponível apenas em inglês, logo, tanto a receita narrada como as ordens dadas pelo usuário também são nesse idioma. Alguns exemplos são: "Stop", "Pause", "Again", "Back", "Continue", "Speak faster", "Help!"10.

O Culinary Pal está conectado ao Allrecipes (allrecipes.com), um dos mais buscados no mundo para receitas e dicas de culinária, divididas em diversas categorias, conforme o site original. Como novidade, o aplicativo também passou a recomendar o acesso ao site CookKoher.com, o que deveria oferecer ao usuário uma experiência mais rápida. Entretanto, nesta pesquisa, apenas foi possível acessar receitas do Allrecipes (Figura 1).

Figura 1 - Exemplo do aplicativo Culinary Pal

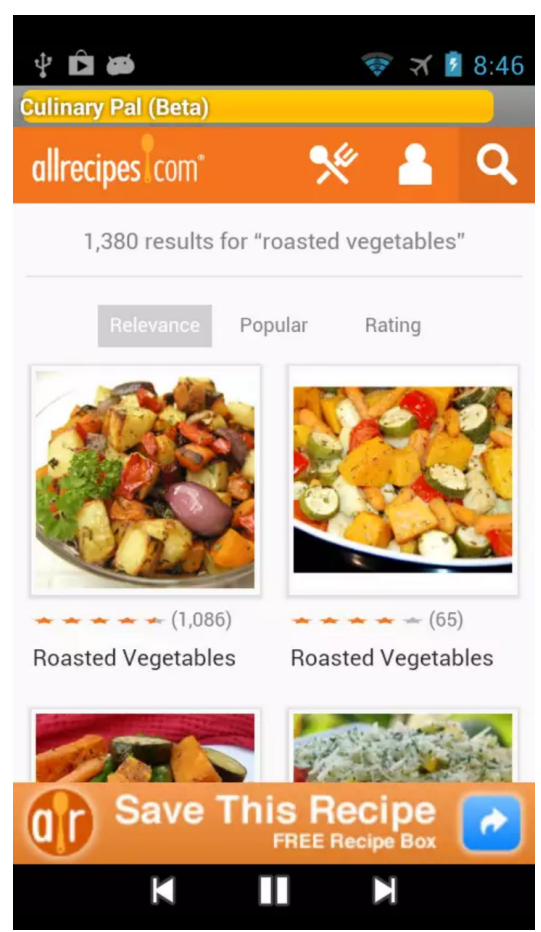

Fonte: Google Play Store. Disponível em: <https://h5.ggpht.com/Cvmugb3tGNXtdFI_mN12vi8YLKz7Uyb_ W45N9Ayacmf0wUItgnByy90H3kFDBT-7Ej7=h900-rw>. Acesso em: 16 set. 2017.

9. No original: "No more printing off recipes, trying to prop open your favorite cookbook, trying to follow a cooking demonstration or risking your computer in the kitchen. No more dirty fingers touching the keypad or transferring bacteria and germs from food to device." Disponível em: <http://www.yizri. com/products/voicesee-culinary-pal/>. Acesso em: 16 set. 2017.

10. Disponível em: <https://play.google.com/store/apps/details?id=com.yizri.voculinary\&hl=pt_BR>. Acesso em: 16 set. 2017. 
A possibilidade de cozinhar com as mãos livres, sem precisar pegar o celular ou tablet, ou olhá-lo para ler a receita, oferecida pelo Culinary Pal por meio de tecnologia de reconhecimento de texto e fala, é estudada por meio das affordances que tal funcionalidade pode oferecer aos usuários, modificando o modo de cozinhar. A questão da materialidade também é discutida para a análise no tópico seguinte.

\section{Affordances e materialidade}

Sem tradução para o português, affordance é uma palavra inglesa que se refere à qualidade de um objeto que permite a identificação de sua funcionalidade sem a necessidade de uma explicação prévia. Isso pode ser feito intuitivamente ou conforme experiências anteriores, por meio de uma "[...] percepção direta, fundamentada na ideia de que a forma de perceber não requer mediadores ou processos internos cognitivos." (CUNHA et al., 2015, p. 20).

"O conceito de affordance é multivalente. [...] é geralmente usado para descrever quais artefatos materiais, como as tecnologias de mídia, permitem que as pessoas façam." "BUCHER; HELMOND, 2017, p. 3. Tradução nossa) ou desenvolvam atividades de acordo com os objetos utilizados. Cunha et al. $(2015$, p. 19) explicam que o termo é derivado do verbo to afford (conceder, permitir, dispor) e destacam três propriedades fundamentais do conceito:

[...] a) de que a affordance existe em relação às capacidades de ação do agente; b) de que a existência de uma affordance independe da habilidade do agente em percebê-la; e c) de que a affordance não se altera como se alteram as necessidades e objetivos de um agente. O conceito clássico utilizado para elucidar estas propriedades é o da superfície horizontal, plana, e extensa que pode permitir (to afford) um apoio. Porém, o que serve de apoio para uma pessoa, pode não servir para outra, dadas as condições de altura e peso do agente e da superfície. O que é affordance para um agente, pode não ser para outro. (CUNHA et al., 2015, p. 19-20, grifos dos autores).

A teoria da affordance prevê uma mutualidade entre o agente e o ambiente que o rodeia, que também pode ser tratada como uma relação entre objeto, usuário e ação. Uma ação executada a partir de uma affordance depende daquilo que o ator consegue captar

11. No original: "The concept of affordance is multivalent. [...] is generally used to describe what material artifacts such as media technologies allow people to do." 
de informação (CUNHA et al., 2015, p. 20). Existem três classificações ${ }^{12}$ de affordances: aparentes; implícitas, mas não aparentes; e ocultas.

Cunha et al. (2015) destacam funcionalidades que geram affordances aparentes nos dispositivos móveis que as incorporam: tactilidade, nivelabilidade, opticabilidade e localibilidade. São características inscritas na materialidade desses objetos e que também interessam para o presente artigo, a fim de auxiliar na análise do aplicativo de gastronomia Culinary Pal. A Figura 2 mostra a divisão dessas funcionalidades.

Figura 2 - Quatro funcionalidades produtoras de affordances nos dispositivos móveis

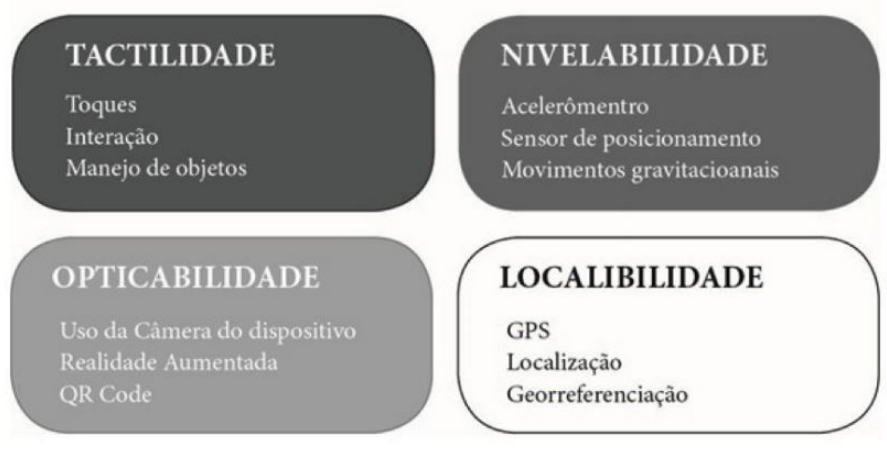

Fonte: Cunha et al., 2015, p. 23.

Tactilidade, segundo os autores, é potencialmente produtora de múltiplos desdobramentos e tem papel fundamental na usabilidade de aplicativos criados para plataformas móveis. Envolve toques, interação e manejo dos objetos. "Está presente em dispositivos com tela sensível ao toque (touchscreen), nos quais o usuário, por meio de toques e gestos, manuseia objetos virtuais presentes nas interfaces." (CUNHA et al., 2015, p. 23). Trata-se de uma funcionalidade essencial para os aplicativos para celulares e tablets, que muda a forma de interação do usuário com o dispositivo. Apesar de o Culinary Pal também propor a sua usabilidade sem a necessidade de encostar as mãos ou dirigir o olhar para o aparelho para a conferência das receitas, ainda assim, a tactilidade é fundamental para se chegar até as telas e para a escolha dos pratos.

A nivelabilidade, por sua vez, abrange o acelerômetro, o sensor de posicionamento e os movimentos gravitacionais. O acelerômetro, presente na maioria dos dispositivos móveis, permite, por exemplo, identificar "[...] níveis de posicionamento e de inclinação

12. Descritas por Cunha et al. (2015) conforme estabelecido por Eric Arnau e Andreu Ballús (2013) com base nas ideias de Gaver (1991). 
[...], bem como possibilita ajustes da tela do aparelho de acordo com o seu ângulo em relação à aceleração gravitacional." (CUNHA et al., 2015, p. 24). A orientação de leitura, com alteração das telas horizontais e verticais conforme o movimento do aparelho, faz parte dessa funcionalidade. Verificou-se que a versão beta do Culinary Pal, que é disponibilizada para esta análise, não fornece a opção de alteração da orientação de leitura, entretanto, entende-se que a nivelabilidade também é essencial para a utilização de grande parte dos aplicativos.

A terceira funcionalidade descrita por Cunha et al. (2015, p. 25-26), a opticabilidade, está relacionada à câmera digital embutida nos dispositivos, o que também possibilita o uso de recursos de realidade aumentada e a leitura de QR Codes. Essa função é muito empregada em aplicativos de gastronomia para o compartilhamento de fotos dos pratos feitos pelos usuários, mas o Culinary Pal não disponibiliza essa opção por ser um App que auxilia na leitura de receitas, sendo agregado a outro site de culinária, no caso o Allrecipes. Diretamente site do Allrecipes o usuário pode explorar esse potencial - ainda que de uma maneira muito embrionária, restrita ao compartilhamento de imagens.

Já a locabilidade inclui GPS, localização e georreferenciação. Essa característica permite a personalização de conteúdos de um aplicativo de acordo com a geolocalização do usuário. Acredita-se que pelo fato de não ser um aplicativo brasileiro ou que produza conteúdo diferenciado para a pessoa (no caso é o usuário que cria o seu "livro" de receitas favoritas), a locabilidade não influencia diretamente no Culinary Pal.

Cunha et al. (2015) complementam que, em geral, em suas atividades, o usuário pode contar com junção de mais de uma potencialidade que produzem affordances específicas conforme as combinações das funcionalidades do dispositivo:

A geração de affordances a partir das funcionalidades presentes em um dispositivo não ocorre somente pela mobilização isolada de potencialidades de cada uma delas, mas pode ocorrer também pela combinação de potencialidades de duas ou mais funcionalidades, gerando affordances que derivam de tais combinações (CUNHA et al., 2015, p. 27, grifos dos autores).

O Culinary Pal, por suas características oferecidas pelo desenvolvedor, possui affordances particulares, como o uso do aplicativo por fones de ouvido com microfone para ouvir as instruções da receita, bem como falar os comandos para prosseguimento da leitura das orientações de ingredientes e do modo de preparo. $\mathrm{O}$ fone de ouvido com 
fio ou por bluetooth também altera o modo de utilização do aplicativo. A inexistência do fio pelo bluetooth deixa o usuário mais independente em suas ações para cozinhar, o que pode tornar a experiência mais eficaz e agradável.

Além das affordances inscritas no Culinary Pal, é importante discutir também a materialidade de um aplicativo para dispositivos móveis. Inicialmente, materialidade parece implicar tangibilidade, objetos que podem ser tocados, compostos por substâncias físicas. No entanto, conforme sugere Leonardi (2010), tem-se debatido cada vez mais sobre a materialidade de artefatos digitais. "A palavra 'material' aqui parece significar uma prática que é fundamentada no cotidiano, no mundo das coisas materiais e pode envolver o intercâmbio ou manipulação de coisas materiais [...]"13 (PINCH, 2008, p. 464 apud LEONARDI, 2010, p. 3. Tradução nossa).

A materialidade também pode se referir à troca de dados e à performatividade, ao fornecer recursos ou habilidades para usuários atingirem seus objetivos (LEONARDI, 2010, p. 3). O autor aponta, ainda, que:

Não importa se esses artefatos são físicos ou digitais, sua "materialidade" é determinada, substancialmente, por quando, como e por que eles são usados. Essas definições implicam que a materialidade não é uma propriedade de artefatos, mas um produto das relações entre artefatos e as pessoas que os produzem e consumem. ${ }^{14}$ (LEONARDI, 2010, p. 9. Tradução nossa).

O autor descreve que os artefatos de caráter virtual "[...] têm uma forma e uma substância que transcendem o espaço e o tempo."15 (LEONARDI, 2010, p. 9, Tradução nossa). Desse modo, o caderno de receitas manuscrito possui uma materialidade tangível e facilmente compreensível, mas podemos considerar que um aplicativo para dispositivos móveis, como o Culinary Pal, também é composto de materialidade. Apesar de sua forma e substância intangíveis, sua materialidade está nas possíveis mudanças e possibilidades que ele é capaz de fornecer aos usuários.

13. No original: "The word 'material' here seems to signify a practice that is grounded in the everyday, in the world of material things and may involve the exchange or manipulation of material things [...]".

14. No original: "No matter whether those artifacts are physical or digital, their "materiality' is determined, to a substantial degree, by when, how, and why they are used. These definitions imply that materiality is not a property of artifacts, but a product of the relationships between artifacts and the people who produce and consume them."

15. No original: "[...] they have a form and substance that transcends space and time." 


\section{Metodologia e análise}

A metodologia escolhida para a pesquisa é a Análise de Conteúdo, “[...] uma técnica de investigação que tem por finalidade a descrição objetiva, sistemática e quantitativa do conteúdo manifesto da comunicação" (BERELSON; LAZARSFELD, 1948 apud BARDIN, 2011, p. 24). A proposta é a detecção dos conteúdos implícitos ou explícitos que são recorrentes ou diferentes entre o aplicativo de gastronomia Culinary Pal e as características comuns dos cadernos de receitas familiares. Para isso, foi desenvolvido um protocolo de análise, inspirado na metodologia apresentada por Débora Oliveira (2013) para a sua pesquisa e nos preceitos descritos por Bardin (2011) e adequado ao presente estudo.

Segundo Bardin (2011, p. 201), a análise categórica temática é uma das técnicas da análise de conteúdo, que funciona por meio de operações de desmembramento do texto ou do objeto analisado em unidades/categorias. A autora ainda aponta que "Classificar elementos em categorias impõe a investigação do que cada um deles tem em comum com os outros. O que vai permitir o seu agrupamento é a parte comum existente entre eles." (BARDIN, 2011, p. 148). Além da categorização, é importante realizar a descrição desses aspectos comparando as suas incidências entre aplicativos para dispositivos móveis e cadernos de receitas.

Em sua pesquisa, Débora Oliveira (2013, p. 55) pretendia - ao comparar dados relativos à apresentação de receitas de cadernos familiares e de publicações impressas antigas e atuais com as divulgadas em sites especializados em culinária - identificar " [...] os indícios de mudanças nas informações das receitas e, consequentemente, compreender como se deu a transição desse conhecimento culinário outrora construído 'de mãe para filha' por meio da experiência cotidiana e da observação.” Aqui, também se objetivou verificar como a transmissão e o compartilhamento dos saberes ligados à cozinha, edificados pela receita, modificam-se com um aplicativo para dispositivos móveis com comando de voz, o que ele mantém das características originais dos cadernos manuscritos e o que ele realmente conta como inovação para os usuários.

- Assim, foram estabelecidas as seguintes categorias de análise ${ }^{16}$ :

- Compartilhamento de receitas com outras pessoas;

- Inclusão de receitas pelo usuário;

- Ranking (estabelecimento de notas ou gradações de qualidade);

16. Também podem ser chamadas de unidade de registro: "É a unidade de significação codificada e corresponde ao segmento de conteúdo considerado unidade de base, visando a categorização e a contagem frequencial. A unidade de registro pode ser de natureza e de dimensões muito variáveis." (BARDIN, 2011, p. 134). 
- Inserção de informações adicionais (dicas, sugestões de variações, informações nutricionais, etc);

- Colocação de comentários;

- Affordances envolvidas.

Culinary Pal é conectado diretamente ao site Allrecipes.com, inclusive com o layout adaptado ao portal; logo, apresenta funções também semelhantes ao Allrecipes. Apesar de poder ser acessado sem a identificação do usuário, é solicitada a criação de um perfil ${ }^{17}$, que é o mesmo para o site como para o Culinary Pal, para que as receitas favoritas possam ser selecionadas, criando uma espécie de caderno personalizado. Portanto, as principais funcionalidades do aplicativo - estudadas, aqui, por meio das categorias de análise desta pesquisa - são oriundas das opções disponibilizadas pelo Allrecipes.com e todas as funcionalidades do site descritas abaixo também são propostas pelo aplicativo ${ }^{18}$.

Um dos propósitos do caderno de receitas manuscrito é a inclusão de receitas pelos seus donos, sejam pratos de família, criados pela própria pessoa, além de rótulos de produtos industrializados, recortes de revistas, cópias de quitutes de programas de TV ou da internet, entre outras. Em geral, o conteúdo vai aumentando e/ou sendo modificado ao longo dos anos. Além de salvar as suas favoritas, o aplicativo propõe que o usuário coloque suas receitas, com todas as instruções e a disponibilização de foto do prato. Ao aderir um novo item, a pessoa decide se será privativo (apenas ele próprio pode ver), publicado em seu profile ou submetido para ser divulgado pelo Allrecipes como Kitchen Approved recipe $^{19}$, concordando com os termos e condições do portal.

O site também permite a formação de uma espécie de rede social digital, aderindo amigos e/ou perfis de outros cozinheiros para seguir e acompanhar suas publicações. A ferramenta possibilita o compartilhamento das receitas, que também pode ser feito por meio das contas em mídias digitais do usuário, como Facebook, Pinterest, Twitter e Google Plus, além do envio por e-mail. Esse compartilhamento de receitas com outras pessoas também pode ocorrer com os cadernos tradicionais, que podem ser emprestados, copiados e reproduzidos. Solange Demeterco (1998, p. 107) ressalta que "A troca de receitas de cozinha reveste-se de um caráter simbólico". A autora aponta que:

17. O perfil pode ser acessado utilizando a conta no Facebook ou do Google ou criando um profile específico com indicação do nome do usuário, e-mail, senha e assinatura dos termos de serviço e política de privacidade. (Disponível em: <https://allrecipes.com/account/signup/>. Acesso em: 30 set. 2017).

18. Conferir ressalvas ao uso do aplicativo que são expostas nas Considerações finais.

19. Receita aprovada pela cozinha (Tradução nossa). São receitas que passam pela revisão editorial do Allrecipes antes de serem publicadas. (Disponível em: $<$ http://allrecipes.com/cook/my/create-recipe/>. Acesso em: 30 set. 2017). 
A transmissão de receitas culinárias remete à ideia de sociabilidade entre grupos e pessoas, especialmente entre uma família, seus membros e indivíduos por ela selecionados para vivenciar a comensalidade. Serão esses momentos, rituais, cerimoniais ou cotidianos que se constituirão na oportunidade (ou às vezes no pretexto) para o preparo de uma 'especialidade culinária', havendo então a possibilidade de realização de uma série de relações sociais, especialmente a troca de receitas, que talvez não acontecesse em outra ocasião. (DEMETERCO, 1998, p. 107).

Com a afirmação de Demeterco (1998), nota-se que a partilha de receitas é incorporada de formas, intenções e cargas simbólicas diferentes em meios impressos tradicionais e digitais.

Assim como o compartilhamento de receitas, a inserção de comentários, com observações e sugestões de alterações, por exemplo, também é possível tanto no aplicativo como nos cadernos manuscritos, apesar de ter conotações diferentes. Nestes, as notas são para uso pessoal (ou familiar), podendo conter acréscimos após a experimentação do preparo. Já no meio digital, em geral, o objetivo é criticar, elogiar, sugerir ou tirar dúvidas sobre a receita, comentários que são divididos com outros usuários. Isso também pode ser feito com a inclusão de informações adicionais, mais comuns no conteúdo do Allrecipes (assim como em livros, aplicativos e sites especializados em gastronomia), que abrange tempo de preparo, número de calorias e rendimento.

Outro ponto analisado é o ranqueamento das receitas. No aplicativo, a avaliação é feita pela opção Rate it (que pode ser traduzida como "Classifique" ou "Avalie"), na qual o usuário dá uma nota à receita usando o símbolo de estrelas, de uma a cinco, com a gradação de "não é comível" até "amei". O usuário também pode acrescentar justificativas para a sua avaliação ou colocar o que deveria ser alterado nos ingredientes ou modo de preparo, por exemplo. É possível identificar esse tipo de ranking também nos cadernos manuscritos, onde as classificações podem ser anotadas com os símbolos de estrela, asterisco ou seta para destacar a receita, como também no título ou por meio de um comentário: "melhor bolo caseiro", "preferido do João" etc., ou, ainda, um risco ou corte para "deletar" e indicar que a receita não deve ser feita ou está incorreta. Aqui há uma potencialização na visibilidade desta avaliação, antes pessoal, restrita, familiar e agora compartilhada publicamente. Além disso, ela não é realizada somente pelo dono do caderno de receitas (impresso ou em app), mas pelos demais sujeitos que compõem direta ou indiretamente sua rede. Esta mudança gera um posicionamento variado do sujeito em relação à disponibilização e adaptação das receitas que encontra. 
Para acessar o site Allrecipes.com, é necessária a verificação em um notebook, celular ou tablet, com um espaço especialmente separado para o equipamento na bancada da cozinha. Demanda pausas no processo de feitura de um prato para leitura das instruções. A pessoa também precisaria interromper o preparo para olhar diretamente para o dispositivo a fim de ler quais são os próximos ingredientes a serem acrescentados ou os passos na execução da receita, também precisando usar os dedos para clicar os comandos ou deslizar pela tela a fim de passar as instruções.

Apesar de formas de uso diferente, com affordances também distintas, o tradicional caderno de receitas também prescinde um espaço na cozinha; neste caso, menos “especial", limpo e seco como carece um aparelho eletrônico. Afinal, é comum os cadernos de receitas serem "sujos" durante o cozinhar, o cuidado dedicado a eles é menor do que ao celular, podendo conter manchas de respingos de ingredientes, por exemplo. Assim, tanto a cabeça (com o olhar) como as mãos também são diretamente implicados na leitura da receita.

O Culinary Pal é uma ferramenta de acesso ao conteúdo do site Allrecipes, cuja tecnologia poderia ser aplicada para outros portais. $\mathrm{O}$ diferencial do aplicativo - quanto à verificação diretamente ao site Allrecipes e ao caderno manuscrito - é a possibilidade de conferir o conteúdo do site original com a tecnologia de reconhecimento de texto e fala, o VoiceSee desenvolvido por YiZRi's Inovations, que permite a consulta às receitas sem a necessidade de utilizar as mãos e direcionar os olhos para leitura das instruções. Assim, além de suas affordances particulares, as demais características analisadas são atributos do Allrecipes, mas incorporadas ao Culinary Pal. Entretanto, são necessárias algumas considerações quanto à eficácia e à eficiência do aplicativo.

O aplicativo, no entanto, explora de maneira reduzida as affordances da rede em que se insere, já que não permite, através do sistema de voz, a postagem de comentários e receitas. Entretanto, integra na experiência a leitura dos comentários que relativizam ou avaliam as receitas, dos ingredientes e modo de fazer. A dinâmica de consumo das receitas, embora muito interessante como proposta, tem um ritmo lento, que não acompanha a fluidez característica da experiência cultural de cozinhar. Ao mesmo tempo, apresenta como ponto positivo a possibilidade de retorno e de adaptação às dinâmicas pessoais de cozinheiros amadores com perfis distintos, que ditam a velocidade de apresentação da receita, as repetições de indicação de ações e comentários de outros leitores.

O dispositivo em si também é, como dissemos, apropriado minimamente, sem incorporações de nivelabilidade, opticabilidade ou localibilidade. O toque e o comando de voz são as ações centrais. Ainda que constituam uma remediação do caderno de receitas, elas são um primeiro passo e precisam ser olhadas sob uma perspectiva crítica. 


\section{Considerações finais}

A análise do aplicativo foi realizada em dois momentos: uma observação do que os desenvolvedores apresentam como proposta e o que se efetiva a partir do consumo do aplicativo conduzido pelos operadores apresentados anteriormente. Atualmente, é disponibilizada na Google Play Store para Android a versão Beta do Culinary Pal. Segundo observação em sua descrição, o aplicativo foi liberado inicialmente em maio de 2012 com uma tecnologia de reconhecimento de fala e texto, mas o desenvolvedor justifica que o Google alterou o serviço de reconhecimento de voz, o que interfere na execução da versão original do Culinary Pal. Logo, um novo design está sendo trabalhado, enquanto disponibilizam o aplicativo experimental ${ }^{20}$.

As versões Beta de um produto ou aplicativo indicam que ele se encontra em fase de desenvolvimento. É mais aceitável para ser lançada aos usuários, porém, ainda possui alguns $b_{u g s}{ }^{21}$, e o desenvolvedor admite isso ${ }^{22}$. Assim, pode ser considerado que o programa ainda não foi finalizado e pode apresentar problemas, mesmo já estando em um nível considerado propício para ser utilizado ${ }^{23}$. Culinary Pal ganhou sua versão beta após o seu desenvolvimento. Durante esta análise, observaram-se alguns erros de execução, além de lentidão no carregamento e na resposta do aplicativo. Isso compromete diretamente a experiência do usuário, e em relação à análise ressalta a falta de ritmo estabelecida entre ele e o app.

Ainda que a utilização do app, devido aos erros identificados na sua execução, não seja fluida, acredita-se que suas características indicam potencialidades de um aplicativo por comando de voz e com as mãos livres, conforme pretende ser o Culinary Pal, como uma inovação no consumo/uso de receitas pelas pessoas.

20. Informações disponíveis na página do Culinary Pal recipes by voice na Play Store: "Please note: This app was initially released in may 2012 as proof-of-concept to provide a glimpse into Yizri's vision of navigating the web and any website hands-free \& eyes-free, backed by 3 patents (uspto 8423365 , 8918323, 9196251). Since then, Google appears to have changed its speech recognition service in a way that interferes with the original implementation. we are working on a new design \& much more. Until then, please consider this app experimental. Thank you." Acesso em: 28 set. 2017.

21. Termo geralmente usado na área da informática, refere-se a algum erro em um programa, software ou aplicativo, quando ele age de modo inesperado, criando falhas em seu uso. (ANDRADE, Gabriel. O que é um bug. InfoEscola. Disponível em: $<$ http://www.infoescola.com/informatica/bug/>. Acesso em: 30 set. 2017).

22. CAMARGO, Camila. O que são versões Alfa, Beta, RC e Final? TEC Mundo, 6 mar. 2009. Disponível em: <https://www.tecmundo.com.br/macos/1698-o-que-sao-versoes-alfa-beta-rc-e-final-.htm>. Acesso em: 28 set. 2017.

23. VERSÃO BETA. In: WIKIPÉDIA - A enciclopédia livre. Disponível em: < https://pt.wikipedia.org/ wiki/Vers\%C3\%A3o_beta $>$. Acesso em: 28 set. 2017. 
Segundo Rogers (1971), inovação é uma ideia, prática ou objeto que é percebida como nova, sendo que a novidade não precisa envolver apenas novos conhecimentos ou a criação de um novo produto. A inovação também está em novos usos ou aplicações de determinado objeto, assim como novos procedimentos para adequar produtos, modos de distribuição e consumo. "Em alguns casos, ela pode apresentar-se sob a forma de sucessivas ondas de mudanças e upgrades que funcionam como um contínuo e gradual desenvolvimento de um produto ou de métodos de produção." (CUNHA et al., 2015, p. 14).

Assim, o Culinary Pal pode ser considerado um processo inovador por oferecer novos formatos e processos de uso e recepção das receitas. A expectativa do uso do app durante o desenvolvimento da fase de análise desta pesquisa era que ele funcionasse conforme as propostas apresentadas por seus desenvolvedores. Porém, conforme dito anteriormente, a sua usabilidade não se mostrou eficaz. Entende-se que, se mais bem desenvolvido, um aplicativo para dispositivos móveis semelhante (cujas funcionalidades e potencialidades realmente sejam efetivadas) pode ser uma inovação capaz de provocar modificações no modo de consumo/consulta a receitas durante o ato de cozinhar.

A análise demonstrou que o aplicativo de receitas busca preservar algumas características importantes dos cadernos manuscritos, como a coleção de receitas conforme as preferências pessoais. Assim, considera-se que um App de gastronomia pode ser considerado uma remediação dos cadernos tradicionais, conforme trabalhos de Bolter e Grusin (2000), por manter suas características originais e oferecer novas potencialidades.

Devido às affordances do app, ele também pode agregar pontos interessantes na transmissão de conhecimentos culinários, principalmente a não necessidade de utilizar as mãos e os olhos no processo de consulta de ingredientes e instruções de preparo das receitas. As "mãos livres" sugeridas pelo Culinary Pal podem acelerar a execução de um prato, como também preservar o dispositivo móvel, pois não haveria o risco de sujar com algum condimento ou deixar cair o celular ao manuseá-lo para conferir um passo da receita. Essas são potencialidades importantes, mas também é preciso considerar a necessidade de um equipamento eficiente (um bom celular ou tablet e, preferencialmente, fones por bluetooth) e de uma internet com conexão muito boa, cujos acessos não são amplamente disponíveis para toda a população. Isso pode tornar o velho caderno de receitas da vovó ainda uma boa ferramenta de consulta e transmissão de conhecimentos culinários. 


\section{Referências}

BARDIN, Laurence. Análise de conteúdo. Tradução de Luís Antero Reto; Augusto Pinheiro. São Paulo: Edições 70, 2011.

BOLTER, Jay David; GRUSIN, Richard. Remediation - Understanding New Media. Massachusetts (EUA): MIT Press, 2000.

BUCHER, Taina; HELMOND, Anne. The Affordances of Social Media Platforms. In: BURGESS, Jean; POELL, Thomas; MARWICK, Aline (Ed.). The SAGE Handbook of Social Media. London; New York: SAGE Publications, 2017. Disponível em: <http://www.annehelmond. nl/wordpress/wp-content/uploads//2016/07/BucherHelmond_SocialMediaAffordances-preprint. pdf $>$. Acesso em: 15 set. 2017.

CANAVILHAS, João; SATUF, Ivan (Orgs.). Jornalismo para Dispositivos Móveis: produção, distribuição e consumo. s/l: Livros Labcom Books, 2015.

CUNHA, Rodrigo; PALACIOS, Marcos; BARBOSA, Suzana; FIRMINO, Fernando. Jornalismo móvel e inovações induzidas por affordances em narrativas para aplicativos em tablets e smartphones. In: CANAVILHAS, João; SATUF, Ivan (Orgs.). Jornalismo para Dispositivos Móveis: produção, distribuição e consumo. s/1: Livros Labcom Books, 2015. p. 7-42.

CARNEIRO, Henrique Soares. Prefácio. In: OLIVEIRA, Débora. Dos cadernos de receitas às receitas de latinha: indústria e tradição culinária no Brasil. São Paulo: Editora Senac São Paulo, 2013. p. 9-12.

DEMETERCO, Solange Menezes da Silva. Doces lembranças: cadernos de receitas e comensalidade. Curitiba 1900-1950. 190f. Dissertação (Mestrado em História) - Setor de Ciências Humanas, Letras e Artes da Universidade Federal do Paraná. Curitiba, 1998.

LEONARDI, Paul M. Digital materiality? How artifacts without matter, matter. First Monday, [S.1.], v. 15, n. 61, jun. 2010. Disponível em: <http://firstmonday.org/ojs/index.php/fm/article/ view/3036/2567>. Acesso em: 28 set. 2017.

MARTINEZ, Lis Yana. Remediation, melhores e mais eficazes maneiras de se comunicar. Organon, Porto Alegre, v. 31, n. 61, p. 323-325, 2016. Disponível em: <http://seer.ufrgs.br/index.php/ organon/article/view/65296/39265>. Acesso em: 10 ago. 2017. 
MARTINO, Luís Mauro Sá. A Teoria da Remediação de Bolter e Grusin. In: Teoria das

Mídias Digitais: linguagens, ambientes, redes. Petrópolis (RJ): Vozes, 2014. p. 221-225.

OLIVEIRA, Débora. Dos cadernos de receitas às receitas de latinha: indústria e tradição culinária no Brasil. São Paulo: Editora Senac São Paulo, 2013.

ORTIZ, Renato. Mundialização e cultura. São Paulo (SP): Editora Brasiliense, 1994.

ROGERS, Everett M. Diffusion of innovations. 2. ed. Nova York: The Free Press, 1971.

TAMXIR. Culinary Pal recipes by voice - Your Hands-free Kitchen Helper. Gizmo's Freeware, 25 mar. 2014. Disponível em: <http://www.techsupportalert.com/content/culinary-pal-recipes-voice-your-hands-free-kitchen-helper.htm>. Acesso em: 16 set. 2017.

VERSÃO BETA. In: WIKIPÉDIA - A enciclopédia livre. Disponível em: < https://pt.wikipedia. org/wiki/Vers\%C3\%A3o_beta >. Acesso em: 28 set. 2017 